\title{
Preparation methods for Graphene, Metal and Polymer-based Composites for EMI Shielding Materials: State of the Art of Conventional and Machine Learning Methods
}

\author{
Saba Ayub 1, Beh Hoe Guan 1,*, Faiz Ahmad 2, Muhammad Faisal Javed 3, Amir Mosavi 4,*, Imre Felde 4 \\ 1 Department of Fundamental and Applied Sciences, Universiti Teknologi PETRONAS, Bandar Seri Iskandar, \\ Perak 32610, Malaysia; saba_20000009@utp.edu.my (S.A.) \\ 2 Department of Mechanical Engineering, Universiti Teknologi PETRONAS, Bandar Seri Iskandar, Perak \\ 32610, Malaysia; faizahmad@utp.edu.my (F.A.) \\ 3 Department of Civil Engineering, COMSATS University Islamabad Abbottabad Campus, Abbottabad \\ 22060, Pakistan; arbabfaisal@cuiatd.edu.pk (M.F.J.) \\ 4 Faculty John von Neumann Faculty of Informatics, Obuda University, 1034 Budapest, Hungary \\ * Correspondence: beh.hoeguan@utp.edu.my (B.H.G.); amir.mosavi@uni-obuda.hu (A.M.)
}

\begin{abstract}
Advancement of the novel electromagnetic inference (EMI) materials is of utmost importance and essential in various industries. The purpose of this study is to present a state-of-theart review on the methods used in the formation of graphene, metal and polymer-based composite EMI materials. The study indicates that in graphene and metal-based composites, the utilization of alternating deposition method provides the highest shielding effectiveness. However, in polymerbased composite, the utilization of chemical vapor deposition method showed the highest shielding effectiveness. Furthermore, this review reveals that there is a gap in the literature in terms of the application of artificial intelligence and machine learning methods. The results further reveal that within the past half a decade the machine learning methods including artificial neural networks had brought significant improvement for modelling EMI materials. Research trend is identified to be in the direction of using advanced forms of machine learning for comparative analysis, research and development employing hybrid and ensemble machine learning methods to deliver higher performance.
\end{abstract}

Keywords: electromagnetic inferences; shielding, graphene; metal; polymer; traditional methods; machine learning

\section{Introduction}

Electromagnetic pollution is increasing in our day to day life which not only affects electronic equipment but is also harmful to human health [1]. The electromagnetic waves damage human health in various forms such as psychological disorders, affect the immune system and also causing a problem in hereditary and with time its impact is increasing which requires vital attention [2]. Electromagnetic shielding history reported back in the early 1830s when Faradays cage was discovered, which is an encircled conductive housing along with zero electric fields [5]. Therefore, there is a need for appropriate materials that acts as a shield to counter electromagnetic waves [6]. Electromagnetic shielding requires a balanced combination between electrical conductivity, dielectric permittivity, and magnetic permeability. It is also observed that the material' morphology plays an important role in electromagnetic shielding and the factors introduce are the reflection, absorption, and multiple reflection losses [7-9].

In a material, the main mechanism for electromagnetic interference attenuation are absorption, reflection and multiple reflections [10]. The reflection is a primary shielding mechanism that occurs in highly electrically conductive structures such as metals. The reflection phenomena depend on mobile charge carriers such as electron which is present 
with in the material. Therefore, the shielding material is likely to be electrically conductive although it is not an essential requirement [11]. The second mechanism for electromagnetic shielding is absorption [12]. It requires the existence of electric and magnetic dipoles to interact with the electromagnetic radiations and greatly depends on the thickness. The third mechanism of electromagnetic shielding is multiple reflections which require large surface areas to interfaces within the shield [13]. The four most common methods used for the measurement of electromagnetic shielding are 1) Open field or free space method 2) Shield box method 3) Shield room method and 4) Coaxial transmission line method [14]. Over the past decade, metals were commonly used materials to overcome the electromagnetic shielding interference issue due to their good electrical conductivity and overall shielding effectiveness, however, metals have many disadvantages such as high mass density, corrosion and difficult processing $[15,16]$. In order to achieve good shielding effectiveness, many other materials are introduced such as carbon, graphene and conducting polymers etc. [16]. Graphene, although is non-metal, yet exhibit properties similar to semi-conducting metals which makes it suitable for electromagnetic inferences (EMI) applications [17-19]. However, conducting polymer have a problem of poor mechanical strength and low processability. The proper distribution of carbon-based filler material within the polymer matrix can be effective to obtain good electromagnetic shielding effectiveness, where polymer-based composite materials improve the absorption and as well a reflection of the incoming radiation [20,21].

The fabrication of materials can be accomplished by using different methods where researchers tried different methods to build a new composite, The selection of methods varies from material to material, for example for the fabrication of metals, friction stir processing and stir casting are mostly used [22]. Similarly for the other materials researcher used different methods according to the properties of materials that are suitable for the preparation of new composites [23]. The selection of an appropriate method plays a vital role in achieving the EMI shielding effectiveness by forming a homogenous sample. Various studies have been conducted on different types of available methods to obtain the maximum EMI shielding of a composite. This review aims to assess the various traditional and artificial intelligence methods to synthesize the shielding composites to deal with EMI. This paper is the perpetuation of the previous review [24] conducted on the applications of graphene, iron and polymer composites in EMI shielding, where the top materials were highlighted in each frequency range to secure good shielding effectiveness. Whereas, in this review preparation methods that help to build the EMI shielding composites have been reviewed. The method selection affects the properties of the material hence impacting the EMI shielding. The scope of this study is limited to review the research articles of Graphene and Metal-based Composites, and Graphene, Metal and Polymer-based Composites formulated through various methods (traditional and artificial intelligence). Although there are many types of carbon materials, yet not all are suitable for EMI applications. Graphene is an emerging material that shows remarkable results as a composite in EMI applications, that is why it was chosen over other types. Another reason for focusing on these materials and their combination is that graphene, metal and polymer-based composites are showing a good performance in EMI applications, therefore reviewing their methods is more pertinent. This study sets a benchmark for future researchers to select the most appropriate method in a selected composite family to formulate a new shielding material.

\section{Review Methodology}

The methodology of this review exhibits the extraction of those articles which were published on the composite formation via traditional methods of various materials as electromagnetic shielding materials. Popular materials such as carbon, graphene, iron and polymer were taken into consideration, as it is important to know about their manufacturing behaviour which impacts significantly on shielding effectiveness. VOSviewer software was used to make keyword analysis of Graphene and Metal-based Composites, and Graphene, Metal and Polymer-based Composites articles. Furthermore, EMI studies 
related to artificial intelligence were also reviewed. A summary of the review methodology is demonstrated in Figure 1.

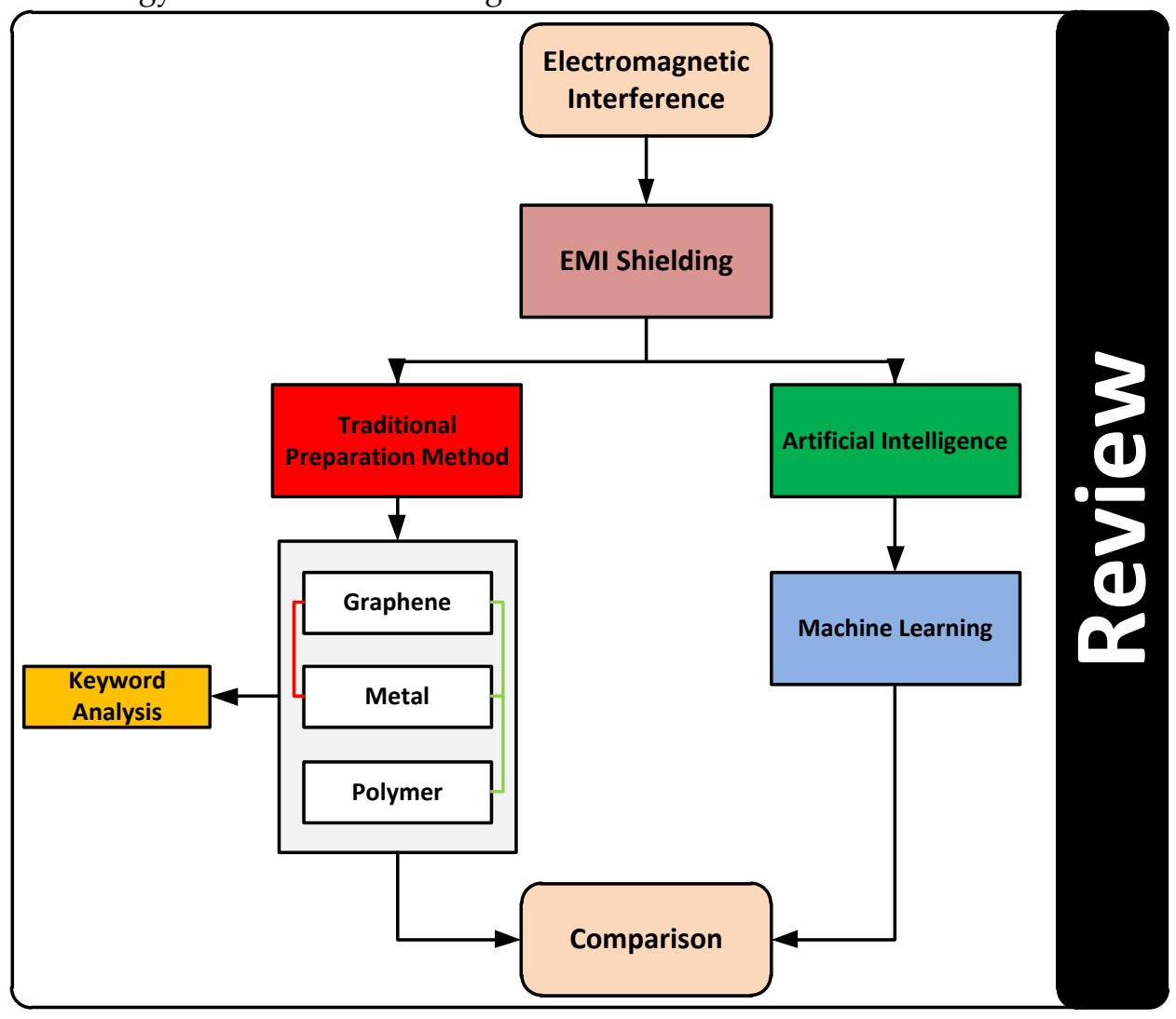

Figure 1. Review flowchart

\section{Interpretation of Articles}

This section covers the summary of the extracted articles (traditional methods) which were published on the preparation methods for graphene, metal and polymer-based composites for EMI shielding materials. Besides that, VOSviewer software was used to show the mapping of the extracted articles based on the keywords co-occurrence.

\subsection{Summary of Extracted Articles}

The English language articles were extracted using the Google Scholar search engine without applying any year limitations. The reason to use Google Scholar for articles extraction is that it covers all the published work from all the journals, either it is the Web of Science index, Scopus index or any other. Figure 2 shows the distribution of the articles of graphene and metal-based composites, and Figure 3 shows the distribution of the articles of polymer-based composites. The number of publications is limited as only those articles were taken into account which comes under the formed combination, i.e. Graphene and Metal-based Composites, and Graphene, Metal and Polymer-based Composites. It can be observed that a gradual increase in the publications occurred over time. An interesting thing which was also observed that with time the focus is more towards the polymer-based composites as it emerged as a promising shielding material. 


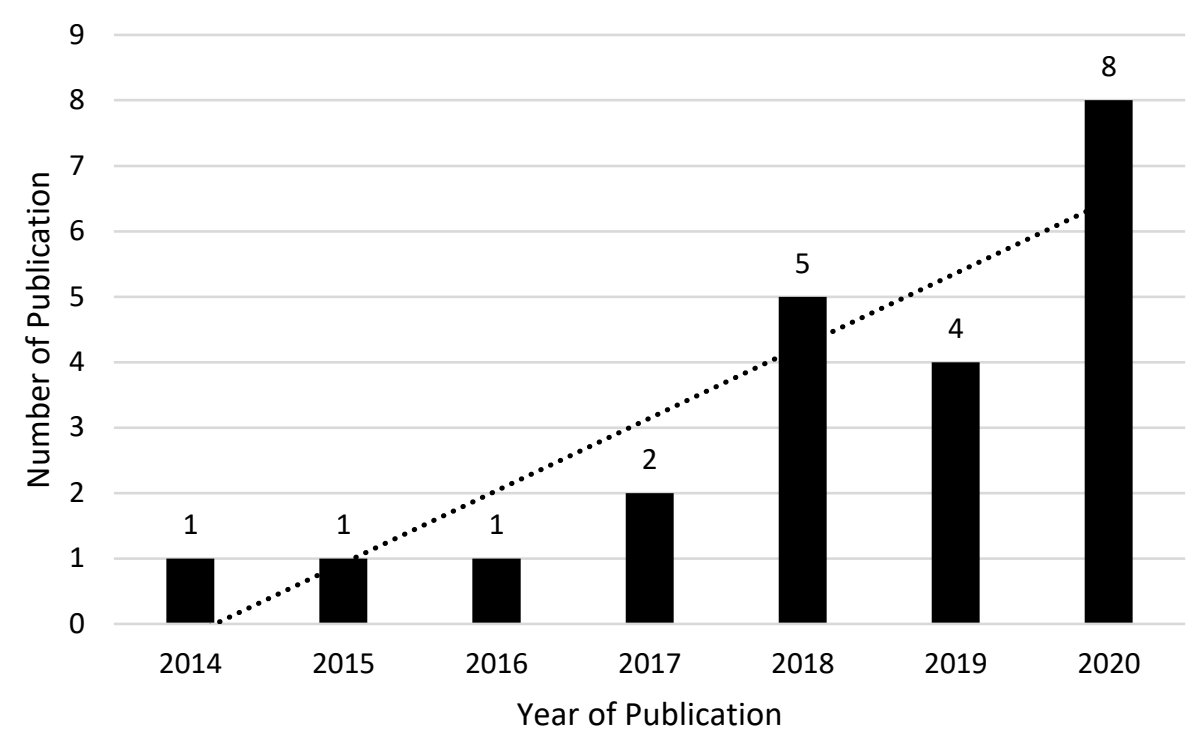

Figure 2. Articles distribution of Graphene and Metal-based Composites.

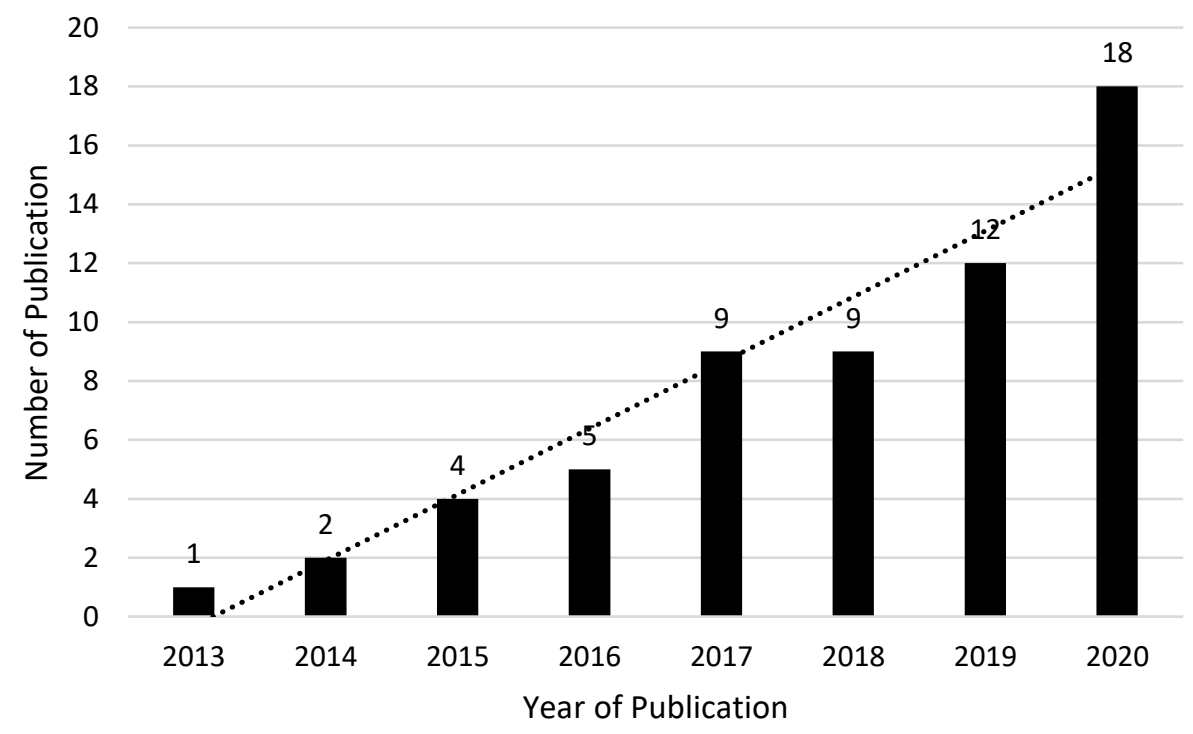

Figure 3. Articles distribution of Polymer-based Composites.

\subsection{Keywords Analysis}

Keywords are an important component of a research article that provides useful information on paper as well as an area of interest. A comprehensive analysis of keywords in various technical fields can help demonstrate trends in research growth and differences. In many papers, co-occurrence analysis of keywords was often used to determine the extent of the relations between different keywords. The link and role of internal materials can be best grasped up in an academic domain by researching keyword co-occurrence relationships and revealing the research limits of the discipline. In the current analysis, a linking of the details based on keywords from the selected papers was generated with the help of VOSviewer software as seen in Figure 4. 


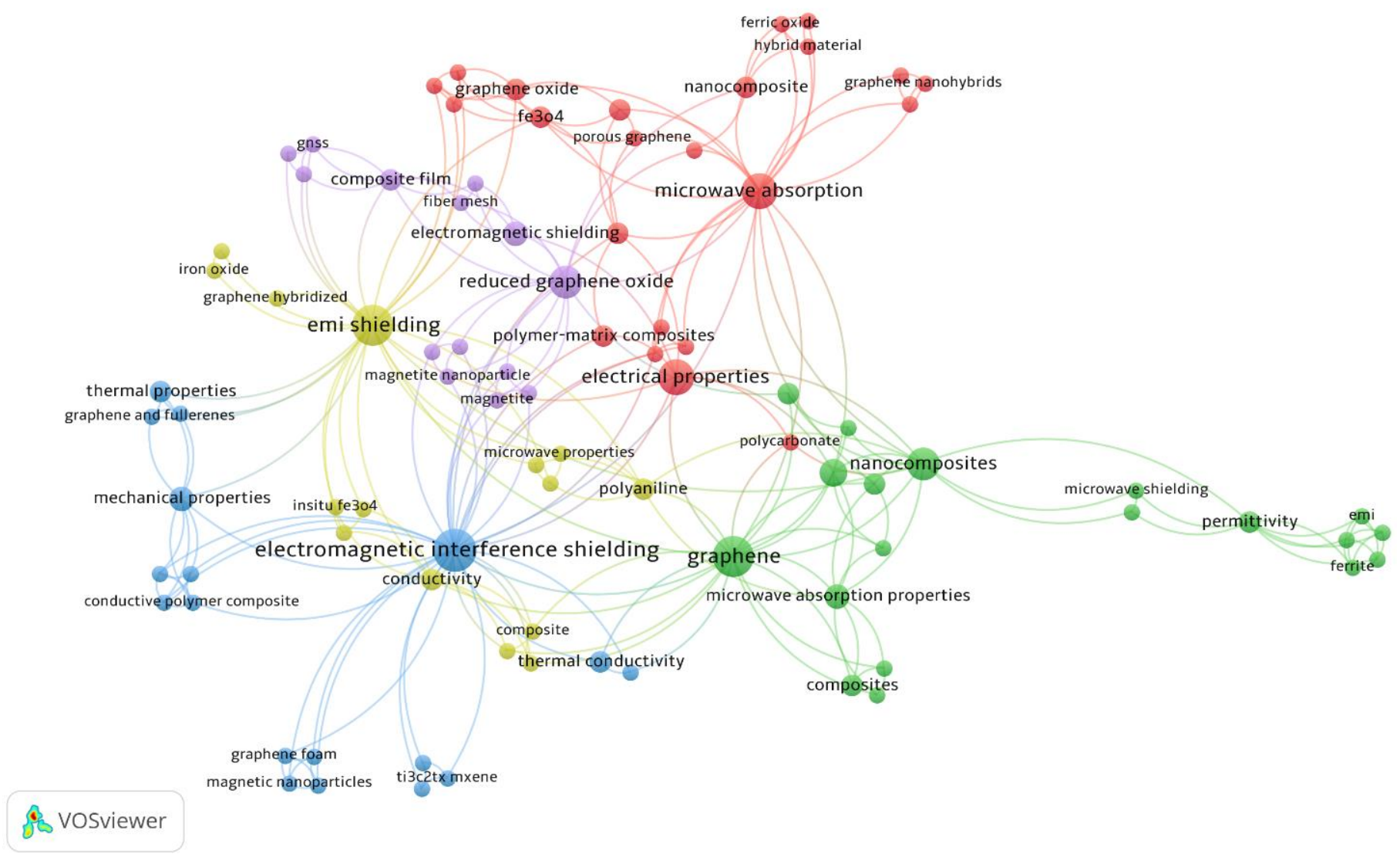

Figure 4. Mapping of Co-occurrence Keywords.

Keyword occurrence was analysed using VOSviewer's "full counting" technologies and a minimal number of keywords occurrence was set to 1 . A total of 89 eligible keywords have been defined by the software that reaches the threshold. The mapping network of 89 linked recurrent keywords with five fuzzy clusters was developed by setting the cluster limit at least 13 cluster keywords. The cluster nodes represent a keyword that associates the connection with other nodes.

Blue nodes with 13 occurrences, which is the first cluster are built on the terminology "Electromagnetic interference shielding". In the same colour pattern, the terms "Mechanical properties", "Thermal properties "and "Thermal conductivity" with occurrences 3 and 2 respectively can also be seen. The following cluster also includes some other keywords and the linkage between all the keywords shows the relation of each keyword in a particular domain. Green nodes with 11 occurrences, which is the second cluster, is built on the terminology "Graphene". In the same colour pattern, few keywords like "nanocomposites", having 6 occurrences and "Microwave absorption properties" with 3 occurrences is also presented. Other keywords such as "absorption properties", "magnetic property" and "permeability" show researchers' interest in this region. Yellow nodes with 11 occurrences, which is the third cluster are built on the terminology "EMI shielding". This cluster is augmented with various polymers keywords like "Single wall carbon nanohorn, "Insitu $\mathrm{Fe}_{3} \mathrm{O}_{4}$ ", "Iron Oxide". The fourth prominent cluster is with red nodes around the term "Microwave absorption" and "Electrical properties" with 8 occurrences both. The fifth prominent cluster is with green nodes having the keywords "Reduced graphene oxide", with 6 occurrences.

\section{Discussion of Articles}

This section covers the compilation of the various methods used for the formulation of carbon, metals, graphene, iron, and polymer family materials. Based on the methods, a discussion has been provided which identify the most suitable methods in each family. The overall summary of the available traditional methods is provided in Table 1. 
Table 1. Various mixing methods.

\begin{tabular}{|c|c|c|c|c|c|}
\hline S. No & Method & Reference & Remarks & Advantage & Disadvantage \\
\hline 1 & $\begin{array}{c}\text { Chemical vapor } \\
\text { deposition }\end{array}$ & [25-27] & $\begin{array}{l}\text { It is a deposition process } \\
\text { performed at high } \\
\text { temperature and gas } \\
\text { pressure and provides } \\
\text { better optical and } \\
\text { electrical properties in } \\
\text { graphene-based } \\
\text { composites. }\end{array}$ & $\begin{array}{ll}\text { - } & \text { Recommended } \\
\text { for coating } \\
\text { - } \quad \text { Gives high } \\
\text { dispersion }\end{array}$ & $\begin{array}{l}\text { - Not suitable for } \\
\text { organic } \\
\text { materials }\end{array}$ \\
\hline 2 & $\begin{array}{l}\text { Alternating } \\
\text { deposition }\end{array}$ & [28] & & Need further exploration. & \\
\hline 3 & $\begin{array}{c}\text { Electrophoretic } \\
\text { deposition }\end{array}$ & {$[29]$} & $\begin{array}{l}\text { Most used process for } \\
\text { material coating }\end{array}$ & $\begin{array}{ll}\text { - } & \text { Easy to use } \\
\text { - } & \text { The deposition } \\
& \text { rate is high } \\
\text { - } & \text { Binder } \\
\text { elimination } \\
\text { - } \\
\text { Can adopt any } \\
\text { shape }\end{array}$ & $\begin{array}{l}\text { - Limited } \\
\text { adhesion }\end{array}$ \\
\hline 4 & In-situ growth & [30-41] & $\begin{array}{l}\text { This technique is a novel } \\
\text { way to implant graphene } \\
\text { layers on metal without } \\
\text { any damage to graphene. } \\
\text { However, structural } \\
\text { control by this technique } \\
\text { needs further } \\
\text { investigation. }\end{array}$ & $\begin{array}{ll}\text { - } & \text { Wrinkle-free } \\
\text { - } & \text { digh-quality } \\
\text { - } & \text { Lithogrsion } \\
& \text { free }\end{array}$ & $\begin{array}{l}\text { - Expensive } \\
\text { procedure } \\
\text { - Time } \\
\text { consuming }\end{array}$ \\
\hline 5 & $\begin{array}{l}\text { Thermal } \\
\text { annealing } \\
\text { method }\end{array}$ & {$[42,43]$} & $\begin{array}{l}\text { This thermal annealing } \\
\text { method used to modify } \\
\text { the surface morphology } \\
\text { of materials with } \\
\text { temperature and time. It } \\
\text { is a mostly useable } \\
\text { method for intrinsic, } \\
\text { structure improving and } \\
\text { surface roughness } \\
\text { control in materials and } \\
\text { is well used for stress } \\
\text { liberation. }\end{array}$ & $\begin{array}{l}\text { - Improve } \\
\text { structure } \\
\text { - Eliminate } \\
\text { surface } \\
\text { roughness }\end{array}$ & $\begin{array}{l}\text { - } \text { Time } \\
\text { consuming }\end{array}$ \\
\hline 6 & $\begin{array}{c}\text { Facile synthetic } \\
\text { route }\end{array}$ & [44-47] & $\begin{array}{l}\text { Mostly a commonly used } \\
\text { method to synthesize } \\
\text { porous structures. }\end{array}$ & $\begin{array}{l}\text { - } \quad \text { Cheap process } \\
\text { Environment } \\
\text { friendly }\end{array}$ & $\begin{array}{l}\text { - Nanoparticles } \\
\text { formation is } \\
\text { slow }\end{array}$ \\
\hline 7 & $\begin{array}{l}\text { Hydrothermal } \\
\text { method }\end{array}$ & {$[41,48-56]$} & $\begin{array}{l}\text { It involves substance } \\
\text { crystallization at high } \\
\text { temperature and } \\
\text { pressure. }\end{array}$ & $\begin{array}{l}\text { - Suitable for the } \\
\text { materials with a } \\
\text { high vapour } \\
\text { pressure } \\
\text { - Form crystalline } \\
\text { phases }\end{array}$ & $\begin{array}{ll}\text { - } & \text { No access to } \\
\text { - } & \text { reaction process } \\
\text { Expensive } \\
\text { autoclave } \\
\text { required }\end{array}$ \\
\hline 8 & $\begin{array}{l}\text { Scalable } \\
\text { method }\end{array}$ & {$[57]$} & & Need further exploration. & \\
\hline
\end{tabular}


This technique is used to form a chemical composite. The benefit of using this technique is that it involves the usage of sol-gel and hydrothermal routes, providing precise control over the shape, size and crystallinity of composites.

Filtrationassisted self-

11

$$
\begin{gathered}
\text { Wet stirring } \\
\text { process }
\end{gathered}
$$

$$
\begin{gathered}
\text { Self-assembly } \\
\text { technique }
\end{gathered}
$$
14 assembly method

Vacuumassisted filtration method

Solution

It is a simple technique of stirring which deals with homogenous mixing of liquids and stir up the solid particle into liquid by using water as a solvent.

In this method without using any external direction among components the disordered system and make it to an organized structure or pattern, it is a low-cost approach for nanofabrication.

It is a promising method to produce low-cost composites. This method is used mostly in organic materials such as polymer-based composites. It is used in different ways through processing method pre-existing components
- Suitable for all types of materials

- Good control over the size and distribution of the material

Need further exploration.
- Easy to use

- Cost efficient
- No access to reaction process

- Expensive autoclave required
- A high amount of diluent is required

\section{- Cheap process \\ - Organized process}

- Time consuming

- High cost
Need further exploration.
- Difficult coating process
- Less expensive ultrasonication and as well stirring for the formation of polymer nanocomposites where the mixing depends on the solvent. A good dispersion of carbon nanofiller in polymer 
matrixes can also be achieved.

In this method, oxidizing agents are used to oxidative polymerization

Co-

16 precipitation method

Centrifugal mixing method

Citrate

Hot-moulding process

21

$$
\begin{gathered}
\text { Mechanical } \\
\text { mixing }
\end{gathered}
$$

Dilute polymerization

High-pressure solid-phase

compression

moulding

Injection

moulding

process graphene oxide in which
It is a chelate-based method that is efficient to reduce the metal ions for nanoparticles fabrication and also stimulate reaction conditions.

This method is a costeffective method and widely used in for mass production of reduced reduction agent used in the form of gas or liquid in graphene oxide for the elimination of functional group.

This process is useful for adding thermoplastic binders to the metallic and ceramic powder to make it fluent. In all this process temperature used above then the melting point.

It is used to form a uniform coat of the particles on the material surface where pellets are followed by a cooling process.

- Mass production

- Cost effective

- Effective for the lesser amount of materials

- Cheap process

- Cheap and easy process

Need further exploration.

It is an old material processing technique. In industrial methods which are used for plastic, it was a commonly used method.
It is a high volume and low-pressure process
- Effective for thermoplastic composite

- $\quad$ Cheap process

- High production rate
- Contamination risk

- Slow process

- High share force not suitable for graphene composite

- Not recommended on high-scale mass production

- Costly for the lesser amount of materials 
Ultrasonication
technique

[90-92]

Hummers method

Hot compressed method

3D printing
method
$[15,98-$ 101] which is performed with
filled thermoplastics.

It is a technique used for the preparation of nanoparticles. It has good control over the structure of the material. method

- Suitable for most of the materials Moreover, with this technique the size of a previously formed composite can also be reduced.

It is a chemical process mostly used to produce graphene from graphite. The hot compression method cannot work at room temperature like

- Controlled structure of materials

- Cheap process

- Time saving

- Highly efficient

- Preferable for smaller production method as it takes place by applying heat to the mould.

- Cheap process

- Time efficient

- Less parameters involved
- High energy consumption
- Release toxic gases during experimentation

- Slow process

- Damaging to moulds

- Contamination risk

- No mass production High cost couple of materials are built simultaneously.

\subsection{Traditional Methods}

4.1.1 Methods for preparation of Graphene and Metal-based Composites

Over the years, graphene has grabbed attention in the field of research due to its tremendous properties. Graphene is wrapped in the honeycomb crystal lattice and is a one atom thick planar sheet [103]. Graphene possesses optical transparency, excellent electrical conductivity, thermal conductivity, mechanical flexibility and low coefficient of thermal expansion behaviour, making it suitable for use in various fields [104]. Similarly, metals can transmit, reflect and absorb EMI and are good electrical conductors as well. Plastics and rubbers are transparent to EMI and are nonconductive as well. Whereas metals have the ability to transmit heat and electricity which makes them good for many applications [105]. Various methods have been used to synthesize the shielding composites with the combination of graphene and metals or both with some other materials as well. A brief description of such methods and the formed composites with shielding effectiveness (SE) has been presented in Table 2. The negative value in the shielding effectiveness (SE) column shows the reflection loss, whereas the positive value is the absorption/total shielding effectiveness.

Table 2. Preparation Methods of Graphene, Metal and Polymer-based Composites.

\begin{tabular}{cccccc}
\hline S. No & Method & Material Composite & SE (dB) & Frequency & Reference \\
\hline \multirow{2}{*}{1} & Chemical vapor & 3DG/Cu & 32.3 & Ku-band & {$[27]$} \\
& deposition & 3D Graphene Network@PDMS & 90 & X-band & {$[25]$} \\
\hline
\end{tabular}




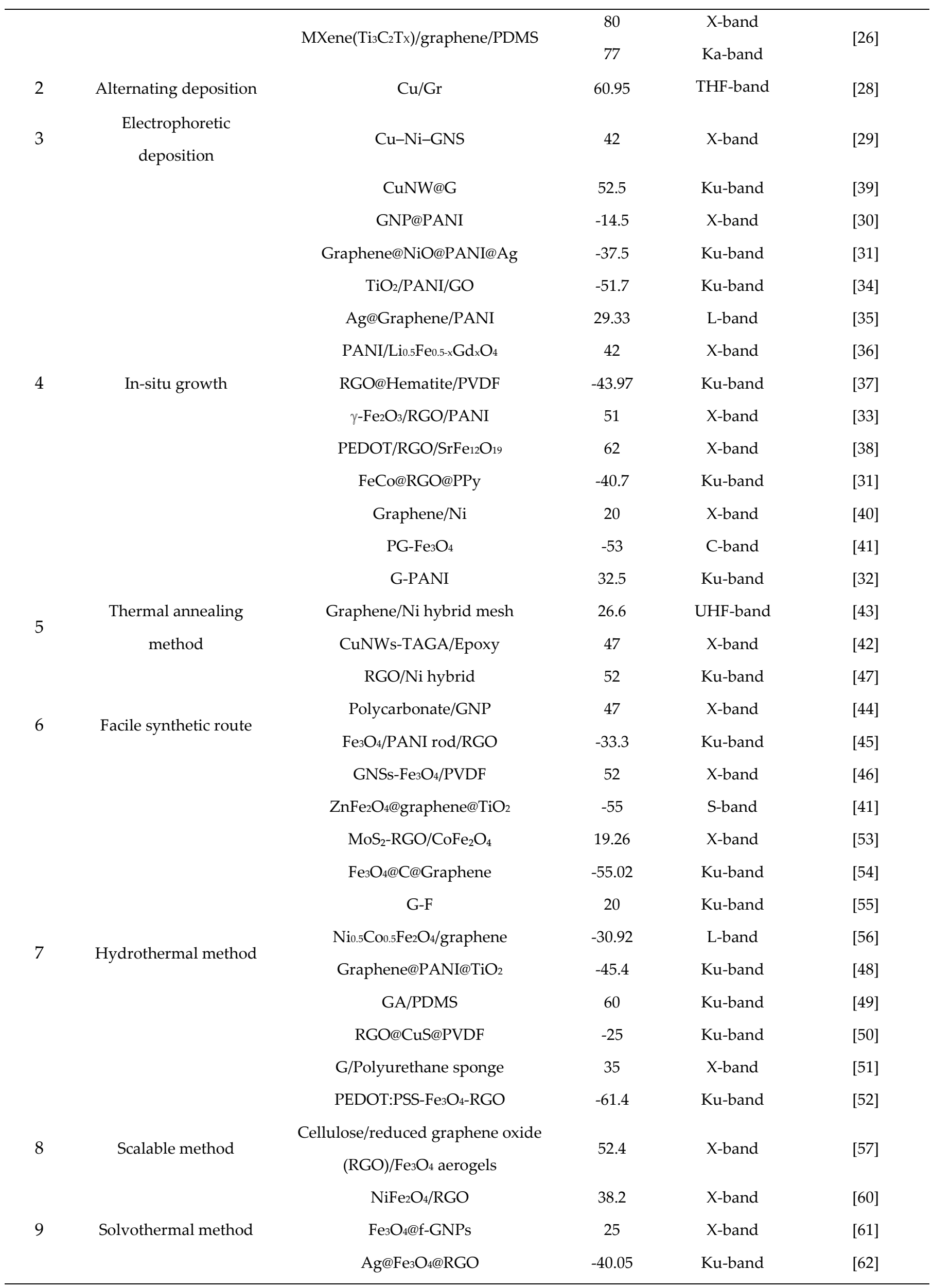




\begin{tabular}{|c|c|c|c|c|c|}
\hline & & $\mathrm{Fe}_{3} \mathrm{O}_{4} @ \mathrm{C} / \mathrm{RGO}$ & -59.23 & Ku-band & [63] \\
\hline & & Hollow Fe $\mathrm{O}_{4} @ \mathrm{GF} @ \mathrm{PDMS}$ & 70.3 & X-band & [58] \\
\hline & & RGO-PEDOT-NiFe2 $\mathrm{O}_{4}$ & -45.4 & & \\
\hline & & RGO-PANI-NiFe ${ }_{2} \mathrm{O}_{4}$ & -49.7 & Ku-band & [59] \\
\hline & & RGO-PPy- $\mathrm{NiFe}_{2} \mathrm{O}_{4}$ & -44.8 & & \\
\hline 10 & $\begin{array}{l}\text { Filtration-assisted self- } \\
\text { assembly method }\end{array}$ & $\mathrm{Fe}_{3} \mathrm{O}_{4}-\mathrm{C}, \mathrm{C}-\mathrm{MIL}-88 \mathrm{~B} / \mathrm{GNP}$ & 28 & X-band & [64] \\
\hline 11 & Wet stirring process & GO@CIP & -56.4 & Ku-band & [65] \\
\hline \multirow{2}{*}{12} & \multirow{2}{*}{ Self-assembly method } & NRMG & 26.4 & X-band & \\
\hline & & PMMA/RGO & 63.2 & X-band & [66] \\
\hline 13 & $\begin{array}{l}\text { Vacuum-assisted } \\
\text { filtration method }\end{array}$ & RGO/CNF@Ag-Fe3 $\mathrm{O}_{4}$ & 21 & X-band & [67] \\
\hline \multirow{10}{*}{14} & & PVC/PANI/GNP & 51 & K-band & [74] \\
\hline & & Gn/SiCnw/PVDF & 32.5 & X-band & [68] \\
\hline & & PVDF/graphene & 47 & X-band & [69] \\
\hline & & $\mathrm{Fe}_{3} \mathrm{O}_{4} @ \mathrm{RGO} / \mathrm{TPU}$ & $\sim 15.51 \pm 1.6$ & X-band & [70] \\
\hline & Solution processing & BaFe@TRGO@TPU & -61 & K-band & [71] \\
\hline & method & $\mathrm{Fe}_{3} \mathrm{O}_{4} @ S L G A P C @ P V A$ & 20 & X-band & [72] \\
\hline & & PVDF/GNP-Ni-CNT & 46.4 & Ku-band & [73] \\
\hline & & $\mathrm{PVDF} / \mathrm{PFC}$ & -29.7 & Ku-band & [75] \\
\hline & & TPU/TRG & 32 & Ku-band & [76] \\
\hline & & RGO/PF/Epoxy & -10.26 & Ku-band & [77] \\
\hline \multirow{4}{*}{15} & & Graphene@Fe3 $\mathrm{O}_{4} @ \mathrm{PANI} @ \mathrm{WO}_{3}$ & -46.7 & X-band & [81] \\
\hline & Chemical oxidative & PEDOT/RGO/PbTiO 3 & 51.94 & Ku-band & [79] \\
\hline & polymerization & $\mathrm{Fe}_{3} \mathrm{O}_{4} / \mathrm{C}: \mathrm{PPy}$ & $>28$ & C-band & [80] \\
\hline & & Polypyrrole/BST/RGO/Fe ${ }_{3} \mathrm{O}_{4}$ & 48 & X-band & [78] \\
\hline \multirow{2}{*}{16} & \multirow{2}{*}{ Co-precipitation method } & $\mathrm{Ti}_{3} \mathrm{C}_{2} \mathrm{~T}_{x} / \mathrm{Fe}_{3} \mathrm{O}_{4} @ \mathrm{PANI}$ & 58.8 & X-band & [82] \\
\hline & & $\mathrm{GNP} / \mathrm{Fe}_{3} \mathrm{O}_{4} / \mathrm{Epoxy}$ & 37.03 & X-band & [83] \\
\hline 17 & $\begin{array}{c}\text { Centrifugal mixing } \\
\text { method }\end{array}$ & TGO/CI/Epoxy & 40 & X-band & [84] \\
\hline 18 & Citrate precursor method & PANI/BF/RGO & 31.1 & X-band & [85] \\
\hline 19 & Chemical reduction & RGO-CF/EP & 37.6 & X-band & [16] \\
\hline 20 & Hot-moulding process & $\mathrm{PVDF} / \mathrm{n}-\mathrm{Fe}$ & 40.21 & Ku-band & [86] \\
\hline 21 & Mechanical mixing & Graphene flakes@PDMS & 31 & THF-band & [87] \\
\hline 22 & Dilute polymerization & Graphene@Fe3 $\mathrm{O}_{4} @ \mathrm{SiO}_{2} @$ polyaniline & -40.7 & X-band & [88] \\
\hline & $\begin{array}{l}\text { High-pressure solid- } \\
\text { phase compression }\end{array}$ & RGO@polystyrene & 45.1 & X-band & [88] \\
\hline 23 & moulding & & & & \\
\hline
\end{tabular}




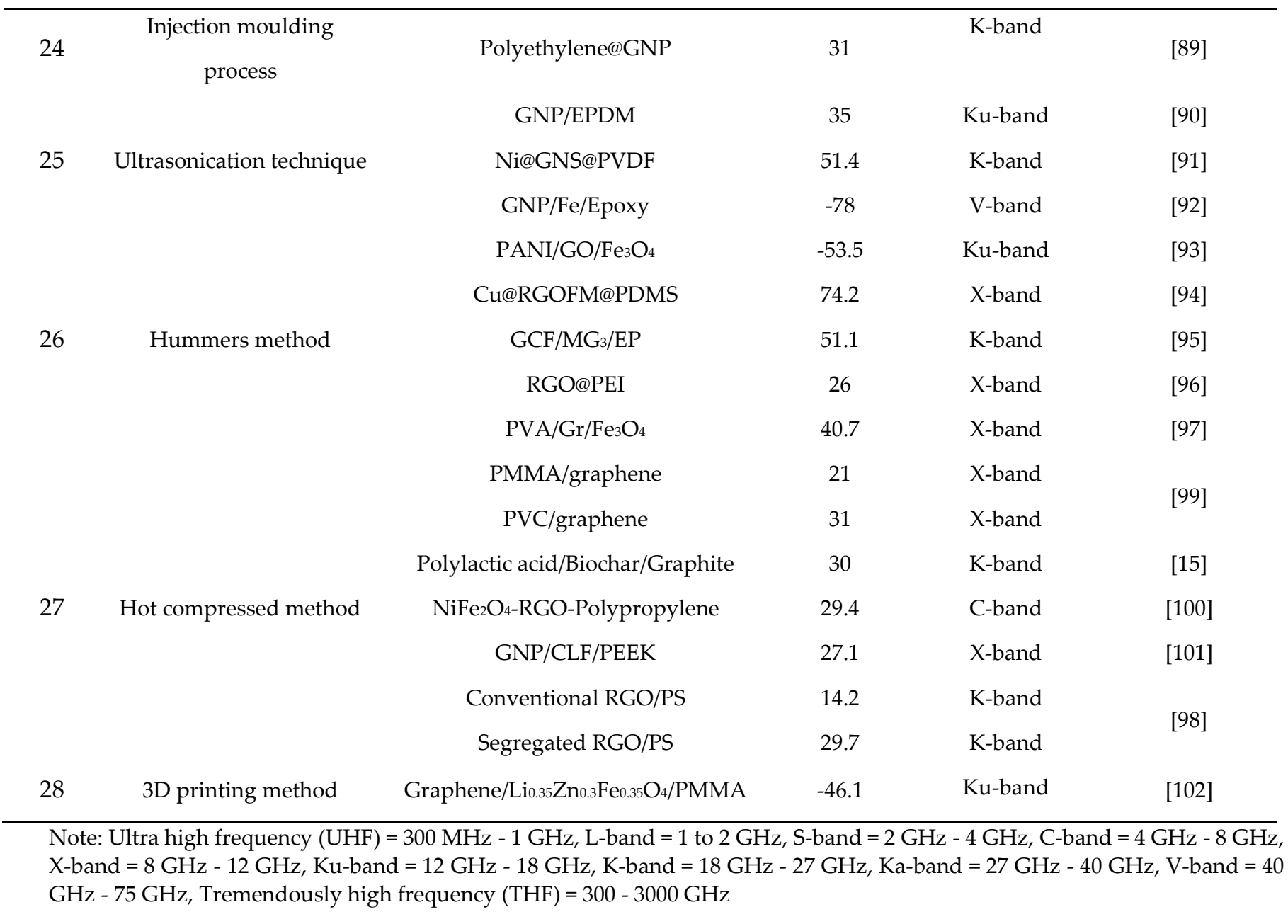

It can be observed that for the preparation of graphene and metal-based composites various methods have been utilized. Interestingly, graphene and metals family materials were constructed with different methods, illustrating that the structure of the material significantly depends on the selected method. Hydrothermal and solvothermal are the two most common methods that have been used extensively for these composites. The composites formed by these methods were tested up to the Ku-band frequency range, where the highest reflection loss of $-55.02 \mathrm{~dB}$ was achieved using hydrothermal and reflection loss of $-59.23 \mathrm{~dB}$ was achieved using the solvothermal method. The highest shielding effectiveness of $52.4 \mathrm{~dB}$ in X-band was achieved via using the scalable method. The higher shielding of $60.95 \mathrm{~dB}$ was achieved in THF-band by alternating deposition where graphene and copper were synthesized. In this case, the role of materials properties also gives significant input. Figure 5 shows the maximum shielding effectiveness achieved by utilizing the various methods in different frequency ranges. 


\section{0}

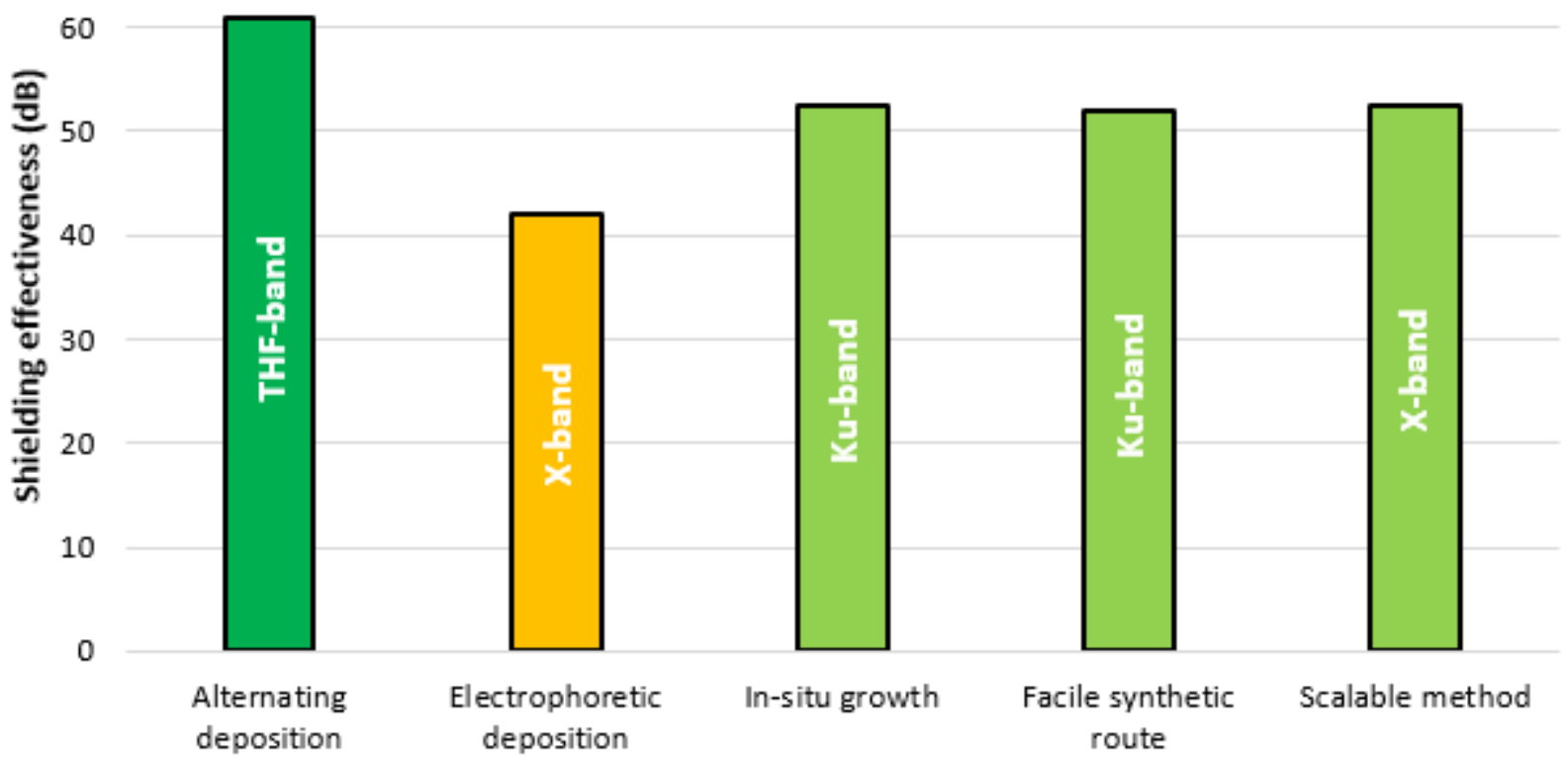

Method

Figure 5. Top 5 methods providing higher SE in Graphene and Metal-based Composites.

It can be observed that in-situ growth, facile synthetic route, and scalable method gives SE greater than $50 \mathrm{~dB}$ in $\mathrm{X}$-band and $\mathrm{Ku}$-band frequency range, whereas, with electrophoretic deposition, the SE was in the range of $40 \mathrm{~dB}$ in X-band. Looking into the combinations of the materials, a scalable method provides better shielding in X-band, while both in-situ growth and facile synthetic route come as the most suitable methods for $\mathrm{Ku}$ band frequency range materials. The highest shielding effectiveness greater than $60 \mathrm{~dB}$ was achieved by alternating deposition in THF-band, however, this method requires further exploration.

\subsubsection{Methods for preparation of Polymer-based Composites}

Graphene and metals although are the most suitable composites for EMI shielding but have some limitations [106, 107]. Due to the advancement in electronic applications, the demand for an effective shielding material has also boost up where thermal expansion, material design flexibility, and non-corrosive properties play a significant role. Besides these properties, the weight-to-strength ratio of EMI shielding materials is also important from the inertia and structural perspective. Moreover, to be part of the electronic system, the material should be lightweight where the polymer composite materials emerge as the most promising materials [108]. Forming a polymer composite, various methods have been used as shown in Table 2.

As shown in Table 2, to form a polymer-based composite, various methods have been used where the most adopted methods are solution processing method, in-situ growth, hydrothermal method, hummers method and solvothermal method. In the X-band frequency range, the highest total shielding effectiveness was achieved up to $90 \mathrm{~dB}$ by utilizing chemical vapor deposition. In Ku-band, the highest total shielding effectiveness was achieved up to $60 \mathrm{~dB}$ with a reflection loss of $-61.4 \mathrm{~dB}$ by making a composite with the hydrothermal method. In the K-band frequency range the maximum total shielding effectiveness of $51.4 \mathrm{~dB}, 51.1 \mathrm{~dB}$ and $51 \mathrm{~dB}$ by using ultrasonication technique, hummers method and solution processing method. While a reflection loss of $-61 \mathrm{~dB}$ was achieved via the solution processing method. In the Ka-band frequency range, the highest total shielding effectiveness of $77 \mathrm{~dB}$ was achieved by using chemical vapor deposition. 
Overall, this method gave better shielding in both X-band and Ka-band. A high reflection loss of $-78 \mathrm{~dB}$ was also observed in the $\mathrm{V}$-band frequency range by the ultrasonication method. A comparison of all the methods has been drawn in Figure 6 which gives shielding effectiveness greater than $50 \mathrm{~dB}$ in their respectable frequency ranges.

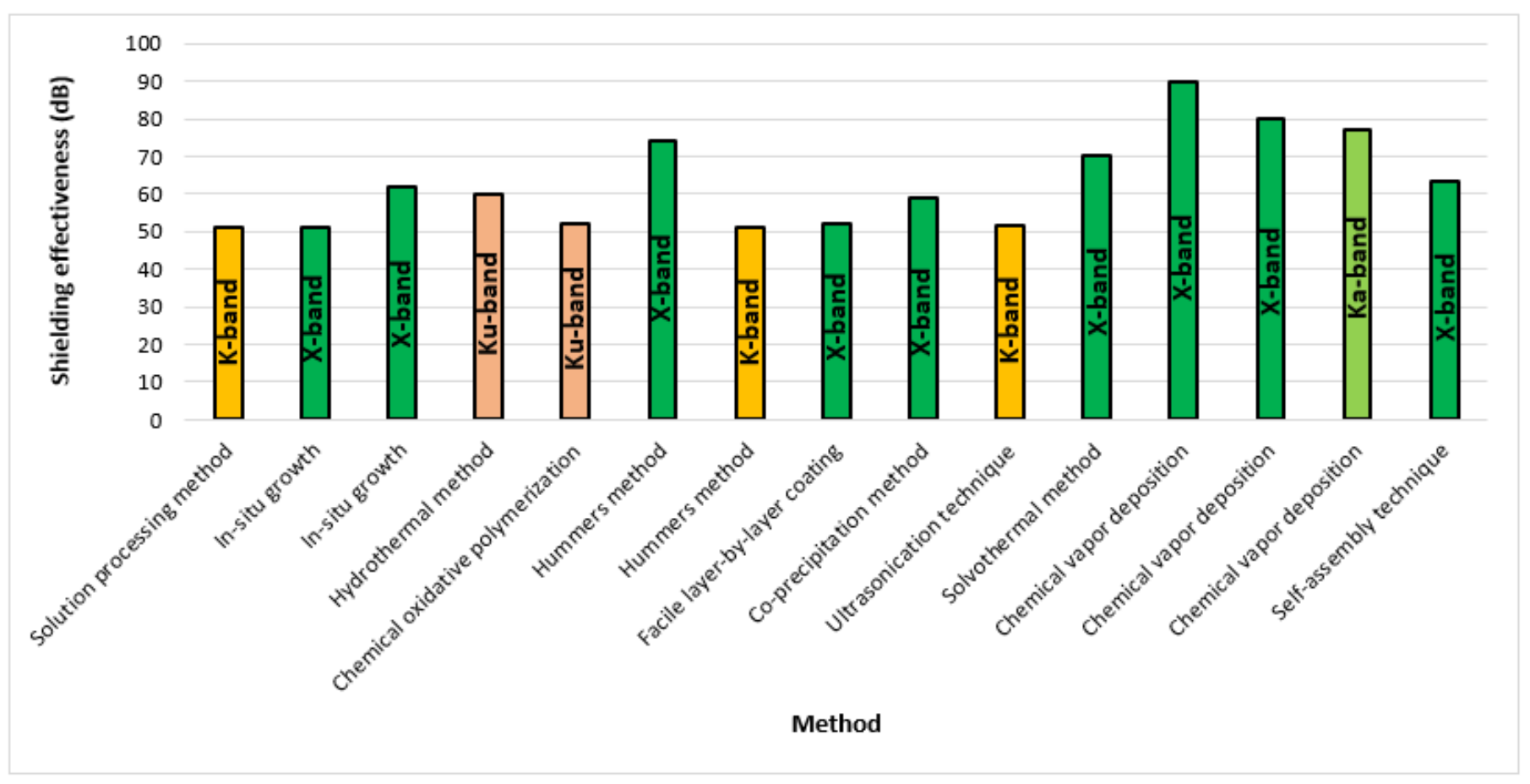

Figure 6. Top methods providing higher SE in Polymer-based Composites.

It can be observed that in the X-band frequency range the highest shielding effectiveness was attained by forming the polymer composite via chemical vapor deposition. In the Ku-band frequency range, the hydrothermal method was more efficient as compared to chemical oxidative polymerization. In the K-band frequency range, solution processing method, hummers method and ultrasonication technique, all performed efficiently. While in Ka-band chemical vapor deposition gives better shielding effectiveness. The overall maximum shielding was achieved by chemical vapor deposition; however, more combinations need to be tested formed by this method.

In this review, the authors tried to draw a comparison of the composite's formation methods for better understanding for future researchers, while performing the review it was observed that this area still needs exploration in terms of comparison of the same composite formed via different methods. In this way, the direction for each composite will be clearer for researchers.

\subsection{Artificial intelligence methods}

Development of artificial intelligence, mainly in machine learning, a variety of reforms have been made in materials formation by exploring new materials and their combinations, along with their properties. This approach is a trending topic as a lot of work is still ongoing [109-111]. The machine learning method has the potential to discover the properties of new composites [112]. However, its benefits are still unrevealed, especially in polymer science $[113,114]$. Various properties of polymers depend on the degree of crystallinity. Machine learning-based methods are competent enough to forecast crystallinity, which can counter the deficiency of traditional methods. With the help of machine learning, melting temperature can also be predicted for new polymers, as its one of the difficult parameters to be controlled in traditional methods [115]. For specific applications, machine learning models are used to identify the properties of the polymer, such as dielectric constant [116] which is a parameter for attaining efficient EMI shielding. 
The composite synthesis requires materials recognition to attain the desirable properties required for specific applications. The traditional methods have been used extensively to evaluate the required properties, based on which further assessment is performed [117]. However, there are various drawbacks of these traditional methods such as time and material consumption, selection of appropriate method for a specific material etc. $[118,119]$. In this manner, machine learning is a tool that can be utilized for quick decisions [120]. Not only it helps in finding the properties, but new materials formation is also possible by its adaptation $[113,121]$. Various machine learning approaches that have been used in EMI are presented in Table 4.

Table 3: Machine learning methods for EMI

\begin{tabular}{|c|c|c|c|c|c|}
\hline S. No & $\begin{array}{l}\text { Machine } \\
\text { learning } \\
\text { Method }\end{array}$ & Reference & Remarks & Advantage & Disadvantage \\
\hline 1 & $\begin{array}{l}\text { Association } \\
\text { rule learning } \\
\text { and decision } \\
\text { tree algorithm }\end{array}$ & [122] & $\begin{array}{l}\text { Effective in dealing with } \\
\text { electromagnetic } \\
\text { interference in high } \\
\text { power line } \\
\text { communication and } \\
\text { helps to eliminate the } \\
\text { troubleshooting }\end{array}$ & $\begin{array}{l}\text { - Normalization } \\
\text { and data scaling } \\
\text { not required }\end{array}$ & $\begin{array}{l}\text { - } \quad \text { Time } \\
\text { consuming }\end{array}$ \\
\hline 2 & $\begin{array}{l}\text { K-nearest } \\
\text { neighbors (k- } \\
\text { NN) algorithm }\end{array}$ & {$[123]$} & $\begin{array}{l}\text { Continuous monitoring } \\
\text { in air traffic control } \\
\text { communication is } \\
\text { applicable against } \\
\text { electromagnetic } \\
\text { interference }\end{array}$ & $\begin{array}{ll}\text { - } & \text { Training period } \\
\text { not required } \\
\text { - } \\
\text { Easy } \\
\text { implementation }\end{array}$ & $\begin{array}{l}\text { - Not suitable for } \\
\text { large and high } \\
\text { dimension data }\end{array}$ \\
\hline 3 & $\begin{array}{l}\text { Artificial } \\
\text { Neural } \\
\text { Networks }\end{array}$ & [124-128] & $\begin{array}{c}\text { An effective approach to } \\
\text { eliminate } \\
\text { electromagnetic } \\
\text { interference problems }\end{array}$ & - $\quad$ Fast evaluation & $\begin{array}{l}\text { Problem } \\
\text { identification is } \\
\text { difficult }\end{array}$ \\
\hline 4 & $\begin{array}{l}\text { Back- } \\
\text { propagation } \\
\text { Neural } \\
\text { Network }\end{array}$ & {$[129,130]$} & $\begin{array}{c}\text { Use backward pass } \\
\text { approach for parameters } \\
\text { adjustment }\end{array}$ & $\begin{array}{l}\text { - Fast and easy to } \\
\text { use }\end{array}$ & $\begin{array}{l}\text { - Actual } \\
\text { performance } \\
\text { depends on } \\
\text { data input for } \\
\text { problem solving }\end{array}$ \\
\hline 5 & $\begin{array}{l}\text { Self-Organizing } \\
\text { Feature Map } \\
\text { Neural } \\
\text { Network }\end{array}$ & {$[131,132]$} & $\begin{array}{c}\text { Effective in evaluating } \\
\text { the global features of } \\
\text { electromagnetic } \\
\text { inferences factors }\end{array}$ & $\begin{array}{l}\text { - Interpretation of } \\
\text { data is easy } \\
\text { Grid clustering } \\
\text { is helpful to } \\
\text { evaluate the } \\
\text { data similarity }\end{array}$ & - $\quad$ Slow training \\
\hline 6 & $\begin{array}{c}\text { Neural } \\
\text { Networks }\end{array}$ & [133-137] & $\begin{array}{c}\text { Effective for } \\
\text { electromagnetic } \\
\text { interference generated } \\
\text { underground metallic } \\
\text { pipelines, high voltage } \\
\text { power lines and other } \\
\text { problems }\end{array}$ & $\begin{array}{l}\text { Detect complex } \\
\text { nonlinear } \\
\text { relationship } \\
\text { Suitable for } \\
\text { multiple } \\
\text { training }\end{array}$ & - $\quad$ Black box \\
\hline 7 & $\begin{array}{l}\text { Monte Carlo } \\
\text { Method }\end{array}$ & {$[138,139]$} & $\begin{array}{c}\text { Effective in } \\
\text { electromagnetic } \\
\text { interference problems }\end{array}$ & $\begin{array}{l}\text { - Flexible } \\
\text { simulation }\end{array}$ & $\begin{array}{ll}\text { - } & \text { Time } \\
\text { consuming }\end{array}$ \\
\hline
\end{tabular}


solving especially in

power lines

It is evident from the above table that various machine learning approaches are available to deal with EMI problems, however, this area requires extensive work as most researchers are focusing on the traditional methods, regardless of their time and cost consuming drawbacks instead of adopting the artificial intelligence. Machine learning methods to evaluate the composite properties and formation needs vital attention as it is the future in material science and can bring major reforms by constructing new composites. With the help of machine learning, materials properties can be pretested, which can be helpful in the construction of the best-suited combination before its experimental formation. Another approach that can be utilized with the help of machine learning is the formation of 3D shielding materials constructed via 3D printing. Such 3D printing can be a time and material saver. The results further reveal that within the past half a decade the machine learning methods including artificial neural networks had brought significant improvement for modelling EMI materials. Research trend is identified to be in the direction of using advanced forms of machine learning for comparative analysis, research and development employing hybrid and ensemble machine learning methods to deliver higher performance. ANN, and advanced forms of neural networks and optimized ANN are the most dominant machine learning methods used.

\section{Future Direction}

The dependency of the traditional method is mainly on the structure of the material which has been taken to form a composite material. Moreover, many new methods have been introduced which needs further investigation to prove their needfulness purposes. Although there are many methods available for the formation of shielding material, very few effective in giving desirable results. However, the area is still unexplored in terms of methods comparison. The opinion of methods selection can be biased as most researchers present their findings as extraordinary without making the comparison. The most suitable way to observe the efficiency of a particular method for any composite is to make the same composite with different available methods and then perform the same analysis, which will give the true picture of the adopted methods. Moreover, the inclusion of machine learning in EMI applications can bring reforms. This is still a gap in this area of knowledge and the investigation will be benchmarking for new researchers as it is time and cost consuming if a wrong method ever adopted. The results further reveal that within the past half a decade the machine learning methods including artificial neural networks had brought significant improvement for modelling EMI materials. Research trend is identified to be in the direction of using advanced forms of machine learning for comparative analysis, research and development employing hybrid and ensemble machine learning methods to deliver higher performance.

\section{Conclusions}

This study is a review of the formation of graphene, metal, and polymer-based composites via various traditional and artificial intelligence methods. The working on graphene and metal-based composites as shielding material exists for a long time, where the addition of polymer-based composites is new and remarkable results have been seen in the field of electromagnetic shielding. An extensive literature was conducted where it was revealed that in graphene and metal-based composites, the alternating deposition method, which is still less explored provide the maximum shielding effectiveness in THF-band. In Ku-band, in-situ growth, while in X-band scalable method utilization provides better shielding effectiveness. In polymer-based composites, the highest shielding effectiveness came when the composite was formed from chemical vapor deposition in X-band. While in Kuband hydrothermal method, in K-band solution processing method, hummers method and ultrasonication technique and in Ka-band chemical vapor deposition utilization provided better shielding effectiveness. However, there is still a gap in the implication of machine learning in EMI applications. The review was conducted with the purpose to highlight the best-suited method for the formation of the composites; however, it is concluded that it is too early to declare any method as 
the best as still there is a gap in this area of knowledge that needs to be filled by making extensive research in which a comparison of the methods should be made for a single composite. The formation of a single composite via various methods upon shielding effectiveness will provide the true picture of the scenario that which is the most suitable methods among the available list in providing the highest shielding effectiveness. The results further reveal that within the past half a decade the machine learning methods including artificial neural networks had brought significant improvement for modelling EMI materials. Research trend is identified to be in the direction of using advanced forms of machine learning for comparative analysis, research and development employing hybrid and ensemble machine learning methods to deliver higher performance.

Author Contributions: All authors contributed equally to this research. All authors have read and agreed to the published version of the manuscript.

Funding: This research has not received any external funding.

Data Availability Statement: data is available upon request.

Acknowledgements: The authors would like to thank Universiti Teknologi PETRONAS (UTP) for the support provided for this research.

Conflicts of Interest: The authors declare no conflict of interest.

\section{References}

1. Raagulan, K., B.M. Kim, and K.Y. Chai, Recent Advancement of Electromagnetic Interference (EMI) Shielding of Two Dimensional (2D) MXene and Graphene Aerogel Composites. Nanomaterials, 2020. 10(4): p. 702.

2. Li, Y., S. Chen, K. Zhao, Y. Gui, S. Fang, Y. Xu, and Z. Ma, Effects of electromagnetic radiation on health and immune function of operators. Zhonghua lao dong wei sheng zhi ye bing za zhi= Zhonghua laodong weisheng zhiyebing zazhi= Chinese Journal of Industrial Hygiene and Occupational Diseases, 2013. 31(8): p. 602-605.

3. Jung, M., Y.-s. Lee, S.-G. Hong, and J. Moon, Carbon nanotubes (CNTs) in ultra-high performance concrete (UHPC): Dispersion, mechanical properties, and electromagnetic interference (EMI) shielding effectiveness (SE). Cement and Concrete Research, 2020. 131: p. 106017.

4. Qin, F. and C. Brosseau, A review and analysis of microwave absorption in polymer composites filled with carbonaceous particles. Journal of applied physics, 2012. 111(6): p. 4.

5. Chung, D., Electromagnetic interference shielding effectiveness of carbon materials. carbon, 2001. 39(2): p. $279-285$.

6. Cheng, K., S. Ramakrishna, and K. Lee, Electromagnetic shielding effectiveness of copper/glass fiber knitted fabric reinforced polypropylene composites. Composites Part A: Applied Science and Manufacturing, 2000. 31(10): p. 1039-1045.

7. Joo, J. and A. Epstein, Electromagnetic radiation shielding by intrinsically conducting polymers. Applied Physics Letters, 1994. 65(18): p. 2278-2280.

8. Saini, P., Electrical properties and electromagnetic interference shielding response of electrically conducting thermosetting nanocomposites. Thermoset Nanocomposites, 2013.

9. Saini, P., Historical review of advanced materials for electromagnetic interference (EMI) shielding: Conjugated polymers, carbon nanotubes, graphene based composites. Indian Journal of Pure \& Applied Physics (IJPAP), 2019. 57(5): p. 338-351.

10. WILEY, Advance materials for electromagnetic sheilding. 2019. https://books.google.com.my/books?id=kGVDwAAQBAJ\&lpg=PA1\&ots=RhoUSihwqR\&dq=EMI\%20related\%20materials\%20and\%20graphs\&lr\&pg=PP1\#v=onepage \&q=EMI\%20related $\% 20$ materials\%20and $\% 20$ graphs\&f=false.

11. Yang, S., K. Lozano, A. Lomeli, H.D. Foltz, and R. Jones, Electromagnetic interference shielding effectiveness of carbon nanofiber/LCP composites. Composites Part A: applied science and manufacturing, 2005. 36(5): p. 691-697.

12. von Klemperer, C.J. and D. Maharaj, Composite electromagnetic interference shielding materials for aerospace applications. Composite Structures, 2009. 91(4): p. 467-472. 
13. Wanasinghe, D. and F. Aslani, A review on recent advancement of electromagnetic interference shielding novel metallic materials and processes. Composites Part B: Engineering, 2019. 176: p. 107207.

14. Geetha, S., K. Satheesh Kumar, C.R. Rao, M. Vijayan, and D. Trivedi, EMI shielding: Methods and materials - A review. Journal of applied polymer science, 2009. 112(4): p. 2073-2086.

15. Tolvanen, J., J. Hannu, M. Hietala, K. Kordas, and H. Jantunen, Biodegradable multiphase poly (lactic acid)/biochar/graphite composites for electromagnetic interference shielding. Composites Science and Technology, 2019. 181: p. 107704.

16. Wu, J., J. Chen, Y. Zhao, W. Liu, and W. Zhang, Effect of electrophoretic condition on the electromagnetic interference shielding performance of reduced graphene oxide-carbon fiberlepoxy resin composites. Composites Part B: Engineering, 2016. 105: p. 167-175. cheaptubes.com. Graphene Synthesis, Properties, And Applications. 2020; Available from: https://www.cheaptubes.com/graphene-synthesis-properties-and-applications/.

18. Ayub, S., B.H. Guan, and F. Ahmad. Graphene and Iron based composites as EMI shielding: A Systematic Review. in 2020 Second International Sustainability and Resilience Conference: Technology and Innovation in Building Designs (51154). 2020. IEEE.

19. Tjaronge, M.W., M.A. Musarat, K. Law, W.S. Alaloul, and S. Ayub. Effect of Graphene Oxide on Mechanical Properties of Rubberized Concrete: A Review. in Proceedings of the International Conference on Civil, Offshore and Environmental Engineering. 2021. Springer.

20. Santhosi, B., K. Ramji, and N.M. Rao, Design and development of polymeric nanocomposite reinforced with graphene for effective EMI shielding in X-band. Physica B: Condensed Matter, 2020: p. 412144.

21. Kim, B.-J., K.-M. Bae, Y.S. Lee, K.-H. An, and S.-J. Park, EMI shielding behaviors of Ni-coated MWCNTs-filled epoxy matrix nanocomposites. Surface and Coatings Technology, 2014. 242: p. 125-131.

22. Ma, Z., Friction stir processing technology: a review. Metallurgical and materials Transactions A, 2008. 39(3): p. $642-658$.

23. Chen, L.-Y., H. Konishi, A. Fehrenbacher, C. Ma, J.-Q. Xu, H. Choi, H.-F. Xu, F.E. Pfefferkorn, and X.-C. Li, Novel nanoprocessing route for bulk graphene nanoplatelets reinforced metal matrix nanocomposites. Scripta Materialia, 2012. 67(1): p. 2932.

24. Ayub, S., B.H. Guan, F. Ahmad, Y.A. Oluwatobi, Z.U. Nisa, M.F. Javed, and A. Mosavi, Graphene and Iron Reinforced Polymer Composite Electromagnetic Shielding Applications: A Review. Polymers, 2021.

25. Ao, D., Y. Tang, X. Xu, X. Xiang, J. Yu, S. Li, and X. Zu, Highly Conductive PDMS Composite Mechanically Enhanced with 3DGraphene Network for High-Performance EMI Shielding Application. Nanomaterials, 2020. 10(4): p. 768.

26. Nguyen, V.-T., B.K. Min, Y. Yi, S.J. Kim, and C.-G. Choi, MXene (Ti3C2TX)/graphene/PDMS composites for multifunctional broadband electromagnetic interference shielding skins. Chemical Engineering Journal, 2020: p. 124608.

27. Cheng, K., W. Xiong, Y. Li, L. Hao, C. Yan, Z. Li, Z. Liu, Y. Wang, K. Essa, and L. Lee, In-situ deposition of three-dimensional graphene on selective laser melted copper scaffolds for high performance applications. Composites Part A: Applied Science and Manufacturing, 2020: p. 105904.

28. Hou, S., W. Ma, G. Li, Y. Zhang, Y. Ji, F. Fan, and Y. Huang, Excellent Terahertz shielding performance of ultrathin flexible Cu/graphene nanolayered composites with high stability. Journal of Materials Science \& Technology, 2020.

29. Ji, K., H. Zhao, Z. Huang, and Z. Dai, Performance of open-cell foam of Cu-Ni alloy integrated with graphene as a shield against electromagnetic interference. Materials Letters, 2014. 122: p. 244-247.

30. Khasim, S., Polyaniline-Graphene nanoplatelet composite films with improved conductivity for high performance X-band microwave shielding applications. Results in Physics, 2019. 12: p. 1073-1081.

31. Wang, Y., X. Wu, W. Zhang, C. Luo, and J. Li, Synthesis of ferromagnetic sandwich FeCo@ graphene@ PPy and enhanced electromagnetic wave absorption properties. Journal of Magnetism and Magnetic Materials, 2017. 443: p. 358-365.

32. Zhou, Y., W. Zhang, Z. Pan, and B. Zhao, Graphene-doped polyaniline nanocomposites as electromagnetic wave absorbing materials. Journal of Materials Science: Materials in Electronics, 2017. 28(15): p. 10921-10928. 
33. Singh, A.P., M. Mishra, P. Sambyal, B.K. Gupta, B.P. Singh, A. Chandra, and S. Dhawan, Encapsulation of $\gamma$-Fe 2 O 3 decorated reduced graphene oxide in polyaniline core-shell tubes as an exceptional tracker for electromagnetic environmental pollution. Journal of Materials Chemistry A, 2014. 2(10): p. 3581-3593.

34. Jia, Q., W. Wang, J. Zhao, J. Xiao, L. Lu, and H. Fan, Synthesis and characterization of TiO2/polyaniline/graphene oxide bouquetlike composites for enhanced microwave absorption performance. Journal of Alloys and Compounds, 2017. 710: p. $717-724$.

35. Chen, Y., Y. Li, M. Yip, and N. Tai, Electromagnetic interference shielding efficiency of polyaniline composites filled with graphene decorated with metallic nanoparticles. Composites Science and Technology, 2013. 80: p. 80-86.

36. Dar, M.A., K. Majid, M. Farukh, S. Dhawan, R. Kotnala, and J. Shah, Electromagnetic attributes a dominant factor for the enhanced EMI shielding of PANI/Li0. 5Fe2. 5- xGdxO4 core shell structured nanomaterial. Arabian Journal of Chemistry, 2019. 12(8): p. 5111-5119.

37. Chen, D., H. Quan, Z. Huang, S. Luo, X. Luo, F. Deng, H. Jiang, and G. Zeng, Electromagnetic and microwave absorbing properties of RGO@ hematite core-shell nanostructure/PVDF composites. Composites science and technology, 2014. 102: p. 126131.

38. Dalal, J., S. Lather, A. Gupta, R. Tripathi, A.S. Maan, K. Singh, and A. Ohlan, Reduced Graphene Oxide Functionalized Strontium Ferrite in Poly (3, 4-ethylenedioxythiophene) Conducting Network: A High-Performance EMI Shielding Material. Advanced Materials Technologies, 2019. 4(7): p. 1900023.

39. Wu, S., M. Zou, Z. Li, D. Chen, H. Zhang, Y. Yuan, Y. Pei, and A. Cao, Robust and stable Cu Nanowire@ Graphene core-shell aerogels for ultraeffective electromagnetic interference shielding. Small, 2018. 14(23): p. 1800634.

40. Zhang, S., Y. Wang, Q. Ran, Q. Fu, and Y. Gu, Electromagnetic interference shielding property of polybenzoxazine/graphene/nickel composites. Reactive and Functional Polymers, 2019. 143: p. 104324.

41. Zheng, Y., X. Wang, S. Wei, B. Zhang, M. Yu, W. Zhao, and J. Liu, Fabrication of porous graphene-Fe3O4 hybrid composites with outstanding microwave absorption performance. Composites Part A: Applied Science and Manufacturing, 2017. 95: p. $237-247$.

Yang, X., S. Fan, Y. Li, Y. Guo, Y. Li, K. Ruan, S. Zhang, J. Zhang, J. Kong, and J. Gu, Synchronously improved electromagnetic interference shielding and thermal conductivity for epoxy nanocomposites by constructing $3 D$ copper nanowires/thermally annealed graphene aerogel framework. Composites Part A: Applied Science and Manufacturing, 2020. 128: p. 105670.

43. Tran, V.V., D.D. Nguyen, A.T. Nguyen, M. Hofmann, Y.-P. Hsieh, H.-C. Kan, and C.-C. Hsu, Electromagnetic Interference Shielding by Transparent Graphene/Nickel Mesh Films. ACS Applied Nano Materials, 2020.

44. Nimbalkar, P., A. Korde, and R. Goyal, Electromagnetic interference shielding of polycarbonate/GNP nanocomposites in X-band. Materials Chemistry and Physics, 2018. 206: p. 251-258.

45. Ma, Y., Y. Zhou, Z. Xiong, Y. Sun, C. Qi, Y. Zhang, and Y. Liu, Facile synthesis of Fe 3 O 4/PANI rod/rGO nanocomposites with giant microwave absorption bandwidth. Journal of Materials Science: Materials in Electronics, 2019. 30(5): p. 4819-4830.

46. Guo, Z., P. Ren, B. Fu, F. Ren, Y. Jin, and Z. Sun, Multi-layered graphene-Fe3O4/poly (vinylidene fluoride) hybrid composite films for high-efficient electromagnetic shielding. Polymer Testing, 2020: p. 106652.

47. Xu, W., G.-S. Wang, and P.-G. Yin, Designed fabrication of reduced graphene oxides/Ni hybrids for effective electromagnetic absorption and shielding. Carbon, 2018. 139: p. 759-767.

48. Liu, P., Y. Huang, J. Yan, and Y. Zhao, Magnetic graphene@ PANI@ porous TiO 2 ternary composites for high-performance electromagnetic wave absorption. Journal of Materials Chemistry C, 2016. 4(26): p. 6362-6370.

49. Ni, J., R. Zhan, J. Qiu, J. Fan, B. Dong, and Z. Guo, Multi-interfaced graphene aerogel/polydimethylsiloxane metacomposites with tunable electrical conductivity for enhanced electromagnetic interference shielding. Journal of Materials Chemistry C, 2020. 8(34): p. 11748-11759.

50. Sharma, D., A.V. Menon, and S. Bose, Graphene templated growth of copper sulphide 'flowers' can suppress electromagnetic interference. Nanoscale Advances, 2020.

51. $\mathrm{Hu}, \mathrm{Z} ., \mathrm{X}$. Ji, B. Li, and Y. Luo, A self-assembled graphene/polyurethane sponge for excellent electromagnetic interference shielding performance. RSC advances, 2019. 9(44): p. 25829-25835. 
52. Wang, X., J.-C. Shu, X.-M. He, M. Zhang, X.-X. Wang, C. Gao, J. Yuan, and M.-S. Cao, Green approach to conductive PEDOT: PSS decorating magnetic-graphene to recover conductivity for highly efficient absorption. ACS Sustainable Chemistry \& Engineering, 2018. 6(11): p. 14017-14025.

53. Prasad, J., A.K. Singh, K.K. Haldar, M. Tomar, V. Gupta, and K. Singh, $\mathrm{CoFe}_{2} \mathrm{O}_{4}$ nanoparticles decorated MoS ${ }_{2}$-reduced graphene oxide nanocomposite for improved microwave absorption and shielding performance. RSC advances, 2019.

54. Zhang, K., Q. Zhang, X. Gao, X. Chen, J. Shi, and J. Wu, Ellipsoidal Fe 3 O 4@ C nanoparticles decorated fluffy structured graphene nanocomposites and their enhanced microwave absorption properties. Journal of Materials Science: Materials in Electronics, 2018. 29(8): p. 6785-6796.

55. Liu, L., X.-M. Bian, Z.-L. Hou, C.-Y. Wang, Z.S. Li, H.D. Hu, X. Qi, and X. Zhang, Electromagnetic response of magnetic graphene hybrid fillers and their evolutionary behaviors. Journal of Materials Science: Materials in Electronics, 2016. 27(3): p. $2760-2772$.

56. Yin, P., Y. Deng, L. Zhang, W. Wu, J. Wang, X. Feng, X. Sun, H. Li, and Y. Tao, One-step hydrothermal synthesis and enhanced microwave absorption properties of Ni0. 5Co0. 5Fe2O4/graphene composites in low frequency band. Ceramics International, 2018. 44(17): p. 20896-20905.

57. Chen, Y., P. Pötschke, J. Pionteck, B. Voit, and H. Qi, Multifunctional Cellulose/rGO/Fe3O4 Composite Aerogels for Electromagnetic Interference Shielding. ACS applied materials \& interfaces, 2020.

58. Fang, H., H. Guo, Y. Hu, Y. Ren, P.-C. Hsu, and S.-L. Bai, In-situ grown hollow Fe3O4 onto graphene foam nanocomposites with high EMI shielding effectiveness and thermal conductivity. Composites Science and Technology, 2020. 188: p. 107975.

59. Yan, J., Y. Huang, X. Chen, and C. Wei, Conducting polymers-NiFe2O4 coated on reduced graphene oxide sheets as electromagnetic (EM) wave absorption materials. Synthetic Metals, 2016. 221: p. 291-298.

60. Kumar, A., A.K. Singh, M. Tomar, V. Gupta, P. Kumar, and K. Singh, Electromagnetic interference shielding performance of lightweight NiFe2O4/rGO nanocomposite in X-band frequency range. Ceramics International, 2020.

61. Jiang, S., K. Qian, K. Yu, H. Zhou, Y. Weng, and Z. Zhang, Controllable synthesis and microwave absorption properties of Fe3O4@ f-GNPs nanocomposites. Composites Communications, 2020: p. 100363.

62. Liu, G., W. Jiang, Y. Wang, S. Zhong, D. Sun, J. Liu, and F. Li, One-pot synthesis of Ag@ Fe3O4/reduced graphene oxide composite with excellent electromagnetic absorption properties. Ceramics International, 2015. 41(3): p. 4982-4988.

63. Zhang, H., Z. Jia, A. Feng, Z. Zhou, L. Chen, C. Zhang, X. Liu, and G. Wu, In situ deposition of pitaya-like Fe3O4@ C magnetic microspheres on reduced graphene oxide nanosheets for electromagnetic wave absorber. Composites Part B: Engineering, 2020. 199: p. 108261.

64. Fei, Y., M. Liang, Y. Chen, and H. Zou, Sandwich-like Magnetic Graphene Papers Prepared with $\mathrm{MOF}-D e r i v e d ~ F e_{3} \mathrm{O}_{4}-\mathrm{C}$ for Absorption-Dominated Electromagnetic Interference Shielding. 2019.

65. Jeon, S., J. Kim, and K.H. Kim, Microwave absorption properties of graphene oxide capsulated carbonyl iron particles. Applied Surface Science, 2019. 475: p. 1065-1069.

66. Sharif, F., M. Arjmand, A.A. Moud, U. Sundararaj, and E.P. Roberts, Segregated hybrid poly (methyl methacrylate)/graphene/magnetite nanocomposites for electromagnetic interference shielding. Acs Applied Materials \& Interfaces, 2017. 9(16): p. 14171-14179.

67. Guo, T., C. Li, Y. Wang, Y. Wang, J. Yue, and X.-Z. Tang, A highly flexible and porous graphene-based hybrid film with superior mechanical strength for effective electromagnetic interference shielding. Applied Physics A, 2020. 126(10): p. 1-8.

68. Liang, C., M. Hamidinejad, L. Ma, Z. Wang, and C.B. Park, Lightweight and flexible graphene/SiC-nanowires/poly (vinylidene fluoride) composites for electromagnetic interference shielding and thermal management. Carbon, 2020. 156: p. 58-66.

69. Sabira, K., M. Jayakrishnan, P. Saheeda, and S. Jayalekshmi, On the absorption dominated EMI shielding effects in free standing and flexible films of poly (vinylidene fluoride)/graphene nanocomposite. European Polymer Journal, 2018. 99: p. 437-444.

70. Hong, S.Y., Y.C. Kim, M. Wang, J.-D. Nam, and J. Suhr, Anisotropic electromagnetic interference shielding properties of polymerbased composites with magnetically-responsive aligned Fe3O4 decorated reduced graphene oxide. European Polymer Journal, 2020: p. 109595. 
71. Zubair, K., M.F. Shakir, A. Afzal, Z. Rehan, and Y. Nawab, Effect of Barium Hexaferrites and Thermally Reduced Graphene Oxide on EMI Shielding Properties in Polymer Composites. Journal of Superconductivity and Novel Magnetism, 2020: p. 1-10.

72. Rao, B.B., P. Yadav, R. Aepuru, H. Panda, S. Ogale, and S. Kale, Single-layer graphene-assembled 3D porous carbon composites with PVA and Fe 3 O 4 nano-fillers: an interface-mediated superior dielectric and EMI shielding performance. Physical Chemistry Chemical Physics, 2015. 17(28): p. 18353-18363.

73. Qi, Q., L. Ma, B. Zhao, S. Wang, X. Liu, Y. Lei, and C.B. Park, An effective design strategy for the sandwich structure of PVDF/GNPNi-CNT composites with remarkable electromagnetic interference shielding effectiveness. ACS Applied Materials \& Interfaces, 2020. 12(32): p. 36568-36577.

74. Shakir, M.F., A.N. Khan, R. Khan, S. Javed, A. Tariq, M. Azeem, A. Riaz, A. Shafqat, H.M. Cheema, and M.A. Akram, EMI shielding properties of polymer blends with inclusion of graphene nano platelets. Results in Physics, 2019. 14: p. 102365.

75. Bera, R., A.K. Das, A. Maitra, S. Paria, S.K. Karan, and B.B. Khatua, Salt leached viable porous Fe3O4 decorated polyanilineSWCNH/PVDF composite spectacles as an admirable electromagnetic shielding efficiency in extended Ku-band region. Composites Part B: Engineering, 2017. 129: p. 210-220.

76. Bansala, T., M. Joshi, S. Mukhopadhyay, R.-a. Doong, and M. Chaudhary, Electrically conducting graphene-based polyurethane nanocomposites for microwave shielding applications in the Ku band. Journal of Materials Science, 2017. 52(3): p. $1546-1560$.

Jaiswal, R., K. Agarwal, R. Kumar, R. Kumar, K. Mukhopadhyay, and N.E. Prasad, EMI and microwave absorbing efficiency of polyaniline-functionalized reduced graphene oxide/ $\gamma$-Fe 2 O 3/epoxy nanocomposite. Soft Matter, 2020. 16(28): p. 6643-6653.

Sambyal, P., S. Dhawan, P. Gairola, S.S. Chauhan, and S. Gairola, Synergistic effect of polypyrrole/BST/RGO/Fe3O4 composite for enhanced microwave absorption and EMI shielding in X-Band. Current Applied Physics, 2018. 18(5): p. 611-618.

Dalal, J., S. Lather, A. Gupta, S. Dahiya, A. Maan, K. Singh, S. Dhawan, and A. Ohlan, EMI shielding properties of laminated graphene and $\mathrm{PbTiO} 3$ reinforced poly (3, 4-ethylenedioxythiophene) nanocomposites. Composites Science and Technology, 2018. 165: p. 222-230.

80. Shukla, V., Role of spin disorder in magnetic and EMI shielding properties of Fe 3 O 4/C/PPy core/shell composites. Journal of Materials Science, 2020. 55(7): p. 2826-2835.

81. Wang, Y., X. Wu, W. Zhang, C. Luo, J. Li, and Q. Wang, 3D heterostructure of graphene@ Fe3O4@WO3@ PANI: preparation and excellent microwave absorption performance. Synthetic Metals, 2017. 231: p. 7-14.

Wang, Z., Z. Cheng, L. Xie, X. Hou, and C. Fang, Flexible and lightweight Ti3C2Tx MXene/Fe3O4@ PANI composite films for high-performance electromagnetic interference shielding. Ceramics International, 2020.

83. Liu, H., C. Liang, J. Chen, Y. Huang, F. Cheng, F. Wen, B. Xu, and B. Wang, Novel 3D network porous graphene nanoplatelets/Fe3O4/epoxy nanocomposites with enhanced electromagnetic interference shielding efficiency. Composites Science and Technology, 2019. 169: p. 103-109.

84. Chen, Y., H.-B. Zhang, Y. Huang, Y. Jiang, W.-G. Zheng, and Z.-Z. Yu, Magnetic and electrically conductive epoxy/graphene/carbonyl iron nanocomposites for efficient electromagnetic interference shielding. Composites Science and Technology, 2015. 118: p. 178-185.

85. Preeti, S., S. Dhawan, A.P. Singh, K. Singh, and A. Ohlan, Nano-ferrite and Reduced Graphene Oxide Embedded in Polyaniline Matrix for EMI Shielding Applications. composites. 12: p. 16.

86. Gargama, H., A. Thakur, and S. Chaturvedi, Polyvinylidene fluoride/nanocrystalline iron composite materials for EMI shielding and absorption applications. Journal of Alloys and Compounds, 2016. 654: p. 209-215.

87. Zdrojek, M., J. Bomba, A. Łapińska, A. Dużyńska, K. Żerańska-Chudek, J. Suszek, L. Stobiński, A. Taube, M. Sypek, and J. Judek, Graphene-based plastic absorber for total sub-terahertz radiation shielding. Nanoscale, 2018. 10(28): p. $13426-13431$.

88. Wang, L., J. Zhu, H. Yang, F. Wang, Y. Qin, T. Zhao, and P. Zhang, Fabrication of hierarchical graphene@ Fe3O4@SiO2@ polyaniline quaternary composite and its improved electrochemical performance. Journal of Alloys and Compounds, 2015. 634: $\mathrm{p}$. 232-238. 
89. Hamidinejad, M., B. Zhao, A. Zandieh, N. Moghimian, T. Filleter, and C.B. Park, Enhanced electrical and electromagnetic interference shielding properties of polymer-graphene nanoplatelet composites fabricated via supercritical-fluid treatment and physical foaming. ACS applied materials \& interfaces, 2018. 10(36): p. 30752-30761.

90. Lu, S., Y. Bai, J. Wang, D. Chen, K. Ma, Q. Meng, and X. Liu, Flexible GnPs/EPDM with excellent thermal conductivity and electromagnetic interference shielding properties. Nano, 2019. 14(06): p. 1950075.

91. Liang, L., P. Xu, Y. Wang, Y. Shang, J. Ma, F. Su, Y. Feng, C. He, Y. Wang, and C. Liu, Flexible polyvinylidene fluoride film with alternating oriented graphene/Ni nanochains for electromagnetic interference shielding and thermal management. Chemical Engineering Journal, 2020: p. 125209.

92. Vovchenko, L., O. Lozitsky, V. Oliynyk, V. Zagorodnii, T. Len, L. Matzui, and Y.S. Milovanov, Dielectric and microwave shielding properties of three-phase composites graphite nanoplatelets/carbonyl iron/epoxy resin. Applied Nanoscience, 2020: p. 1-10.

93. Zhao, J., J. Lin, J. Xiao, and H. Fan, Synthesis and electromagnetic, microwave absorbing properties of polyaniline/graphene oxide/Fe 3 O 4 nanocomposites. RSC advances, 2015. 5(25): p. 19345-19352.

94. Li, M., K. Yang, W. Zhu, J. Shen, J. Rollinson, M. Hella, and J. Lian, Copper-Coated Reduced Graphene Oxide Fiber Mesh-Polymer Composite Films for Electromagnetic Interference Shielding. ACS Applied Nano Materials, 2020.

95. Wu, J., Z. Ye, H. Ge, J. Chen, W. Liu, and Z. Liu, Modified carbon fiber/magnetic graphenelepoxy composites with synergistic effect for electromagnetic interference shielding over broad frequency band. Journal of colloid and interface science, 2017. 506: p. 217-226.

96. Sawai, P., P. Chattopadhaya, and S. Banerjee, Synthesized reduce Graphene Oxide (rGO) filled Polyetherimide based nanocomposites for EMI Shielding applications. Materials Today: Proceedings, 2018. 5(3): p. 9989-9999.

97. Khodiri, A.A., M.Y. Al-Ashry, and A.G. El-Shamy, Novel hybrid nanocomposites based on polyvinyl alcohol/graphene/magnetite nanoparticles for high electromagnetic shielding performance. Journal of Alloys and Compounds, 2020. 847: p. 156430.

98. Shahzad, F., S.H. Lee, S.M. Hong, and C.M. Koo, Segregated reduced graphene oxide polymer composite as a high performance electromagnetic interference shield. Research on Chemical Intermediates, 2018. 44(8): p. 4707-4719.

99. Joseph, J., A.K. Koroth, D.A. John, A.M. Sidpara, and J. Paul, Highly filled multilayer thermoplastic/graphene conducting composite structures with high strength and thermal stability for electromagnetic interference shielding applications. Journal of Applied Polymer Science, 2019. 136(29): p. 47792.

100. Yadav, R.S., I. Kuřitka, J. Vilčáková, M. Machovský, D. Škoda, P. Urbánek, M. Masař, M. Gořalik, M. Urbánek, and L. Kalina, Polypropylene nanocomposite filled with spinel ferrite NiFe2O4 nanoparticles and in-situ thermally-reduced graphene oxide for electromagnetic interference shielding application. Nanomaterials, 2019. 9(4): p. 621.

101. Li, S., W. Li, J. Nie, D. Liu, and G. Sui, Synergistic effect of graphene nanoplate and carbonized loofah fiber on the electromagnetic shielding effectiveness of PEEK-based composites. Carbon, 2019. 143: p. 154-161.

102. Zuo, Y., X. Su, X. Li, Z. Yao, T. Yu, J. Zhou, J. Li, J. Lu, and J. Ding, Multimaterial 3D-Printing of Graphene/Li0. 35Zn0. 3Fe2. 3504 and graphene/carbonyl iron composites with superior microwave absorption properties and adjustable bandwidth. Carbon, 2020.

103. Sur, U.K., Graphene: a rising star on the horizon of materials science. International Journal of Electrochemistry, 2012.2012.

104. Hansora, D., N. Shimpi, and S. Mishra, Graphite to graphene via graphene oxide: an overview on synthesis, properties, and applications. Jom, 2015. 67(12): p. 2855-2868.

105. Wohlford, T., J. Schaaf, L. Taylor, T. Furtsch, E. Khor, A. St Clair, and R. Seymour, Conductive Polymers. Plenum, New York, 1981.

106. Yasufuku, S., Technical progress of EMI shielding materials in Japan. IEEE electrical insulation magazine, 1990. 6(6): p. 21-30.

107. Chandra, R.J., B. Shivamurthy, S.D. Kulkarni, and M.S. Kumar, Hybrid polymer composites for EMI shielding application-a review. Materials Research Express, 2019. 6(8): p. 082008.

108. Luo, X. and D. Chung, Electromagnetic interference shielding using continuous carbon-fiber carbon-matrix and polymer-matrix composites. Composites Part B: Engineering, 1999. 30(3): p. 227-231.

109. Mannodi-Kanakkithodi, A., A. Chandrasekaran, C. Kim, T.D. Huan, G. Pilania, V. Botu, and R. Ramprasad, Scoping the polymer genome: A roadmap for rational polymer dielectrics design and beyond. Materials Today, 2018. 21(7): p. 785-796. 
110. Sanchez-Lengeling, B. and A. Aspuru-Guzik, Inverse molecular design using machine learning: Generative models for matter engineering. Science, 2018. 361(6400): p. 360-365.

111. Butler, K.T., D.W. Davies, H. Cartwright, O. Isayev, and A. Walsh, Machine learning for molecular and materials science. Nature, 2018. 559(7715): p. 547-555.

112. Hamidi, Y.K., A. Berrado, and M.C. Altan. Machine learning applications in polymer composites. in AIP Conference Proceedings. 2020. AIP Publishing LLC.

113. Wu, S., Y. Kondo, M.-a. Kakimoto, B. Yang, H. Yamada, I. Kuwajima, G. Lambard, K. Hongo, Y. Xu, and J. Shiomi, Machinelearning-assisted discovery of polymers with high thermal conductivity using a molecular design algorithm. Npj Computational Materials, 2019. 5(1): p. 1-11.

114. Kim, C., R. Batra, L. Chen, H. Tran, and R. Ramprasad, Polymer design using genetic algorithm and machine learning. Computational Materials Science, 2021. 186: p. 110067.

115. Venkatram, S., R. Batra, L. Chen, C. Kim, M. Shelton, and R. Ramprasad, Predicting crystallization tendency of polymers using multifidelity information fusion and machine learning. The Journal of Physical Chemistry B, 2020. 124(28): p. 6046-6054.

116. Chen, L., C. Kim, R. Batra, J.P. Lightstone, C. Wu, Z. Li, A.A. Deshmukh, Y. Wang, H.D. Tran, and P. Vashishta, Frequencydependent dielectric constant prediction of polymers using machine learning. npj Computational Materials, 2020. 6(1): p. 1-9.

117. Sharma, V., C. Wang, R.G. Lorenzini, R. Ma, Q. Zhu, D.W. Sinkovits, G. Pilania, A.R. Oganov, S. Kumar, and G.A. Sotzing, Rational design of all organic polymer dielectrics. Nature communications, 2014. 5(1): p. 1-8.

118. Huan, T.D., A. Mannodi-Kanakkithodi, and R. Ramprasad, Accelerated materials property predictions and design using motifbased fingerprints. Physical Review B, 2015. 92(1): p. 014106.

119. d'Avezac, M., J.-W. Luo, T. Chanier, and A. Zunger, Genetic-algorithm discovery of a direct-gap and optically allowed superstructure from indirect-gap Si and Ge semiconductors. Physical review letters, 2012. 108(2): p. 027401.

120. Mannodi-Kanakkithodi, A., G. Pilania, T.D. Huan, T. Lookman, and R. Ramprasad, Machine learning strategy for accelerated design of polymer dielectrics. Scientific reports, 2016. 6(1): p. 1-10.

121. Zhou, T., Z. Song, and K. Sundmacher, Big data creates new opportunities for materials research: A review on methods and applications of machine learning for materials design. Engineering, 2019. 5(6): p. 1017-1026.

122. Tian, H., Y. Zhao, L. Kang, Y. Shang, and X. Liu. Electromagnetic Interference Diagnosis Based on HPLC Timing Sequence Topology and Machine Learning. in IOP Conference Series: Earth and Environmental Science. 2019. IOP Publishing.

123. Eliardsson, P. and P. Stenumgaard. Artificial Intelligence for Automatic Classification of Unintentional Electromagnetic Interference in Air Traffic Control Communications. in 2019 International Symposium on Electromagnetic Compatibility-EMC EUROPE. 2019. IEEE.

124. Wei, X., Y. Shu, Z. Hu, Y. Zhong, and Y. Wang. A Summary of Artificial Neural Networks on Electromagnetic Interference Diagnosis. in 2019 International Conference on Microwave and Millimeter Wave Technology (ICMMT). 2019. IEEE.

125. Shu, Y.-F., X.-C. Wei, J. Fan, R. Yang, and Y.-B. Yang, An equivalent dipole model hybrid with artificial neural network for electromagnetic interference prediction. IEEE Transactions on Microwave Theory and Techniques, 2019. 67(5): p. 1790-1797.

126. Hu, Z.-K., Y.-H. Zhong, X.-C. Wei, Y.-W. Wang, and Y.-F. Shu. A Novel Electromagnetic Interference Source Reconstruction Method based on Artificial Neural Network. in 2018 12th International Symposium on Antennas, Propagation and EM Theory (ISAPE). 2018. IEEE.

127. Yan, L., X. Zhao, H. Zhao, H. Zhou, and K. Huang, Artificial neural network modeling of electromagnetic interference caused by nonlinear devices inside a metal enclosure. Journal of Electromagnetic Waves and Applications, 2015. 29(8): p. 992-1004.

128. Ellithy, K., A. Al-Badi, and S. Al-Alawi, An artificial neural network model for predicting electromagnetic interference effects on gas pipelines built in power lines row. Engineering Intelligent Systems, 2004. 12(4): p. 229-235.

129. Zhou, C., Z. Wang, T. Liu, S. Zhao, and Z. Liang, Low dropout linear regulator's electromagnetic interference damage model based on BP neural network. High Voltage Engineering, 2016. 42(3): p. 973-979. 
130. Qishuang, Y.T.M. and X. Qingming, Prediction of electromagnetic interference based on neural network. Journal of Beijing University of Aeronautics and Astronautics, 2013: p. 05.

131. Li, H., D. Zhao, S. Xu, P. Wang, and J. Chen, High Dimensional Electromagnetic Interference Signal Clustering Based On SOM Neural Network. ELECTRONICS, 2016. 20(1): p. 27-31.

132. Masugi, M., Self-organizing neural network-based analysis of electrostatic discharge for electromagnetic interference assessment. IEICE transactions on communications, 2003. 86(6): p. 1991-2000.

133. Micu, D.D., L. Czumbil, G. Christoforidis, and E. Simion, Neural networks applied in electromagnetic interference problems. Revue Roumain des Sciences Techniques, Serie Electrotechnique et Energetique, 2012. 57(2): p. 162-171.

134. Micu, D.D., L. Czumbil, G. Christoforidis, and A. Ceclan, Layer recurrent neural network solution for an electromagnetic interference problem. IEEE transactions on magnetics, 2011. 47(5): p. 1410-1413.

135. Micu, D.D., L. Czumbil, A. Ceclan, L. Darabant, D. Stet, and G. Christoforidis. Electromagnetic interferences between HV power lines and metallic pipelines evaluated with neural network technique. in 2009 10th International Conference on Electrical Power Quality and Utilisation. 2009. IEEE.

136. Micu, D.D., L. Czumbil, A. Ceclan, E. Simion, D. Stet, and L. Cîmpan, Neural Network Evaluation of Electromagnetic Interferences between HV Power Lines and Underground Metallic Pipelines. Journal of Electrical and Electronics Engineering, 2009(1): p. 73.

137. Czumbil, L., D. Micu, and A. Ceclan. Artificial Intelligence Techniques Applied to Electromagnetic Interference Problems. in International Conference on Advancements of Medicine and Health Care through Technology. 2009. Springer.

138. Micu, D.D., L. Czumbil, A. Polycarpou, A. Ceclan, and L. Cimpan. Analysis of electromagnetic interference problems proposed to be through an innovative Monte Carlo-Neural Network method. in 7th Mediterranean Conference and Exhibition on Power Generation, Transmission, Distribution and Energy Conversion (MedPower 2010). 2010. IET.

139. Micu, D.D., L. Czumbil, G. Christoforidis, and A. Ceclan. Proposed Monte Carlo-Neural Network method for solving electromagnetic interference problems. in 45th International Universities Power Engineering Conference UPEC2010. 2010. IEEE. 